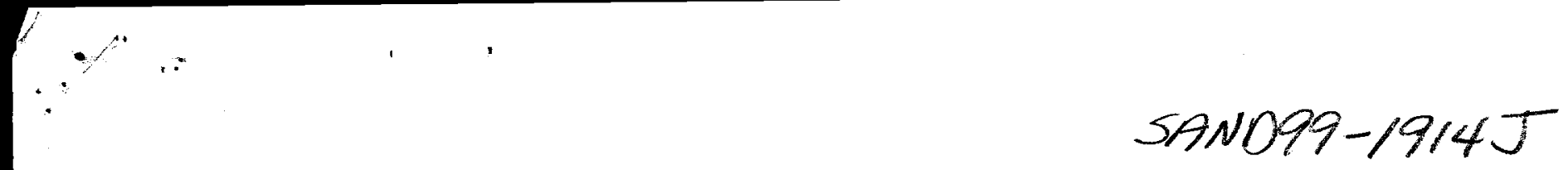

\title{
Oxygen Implant Isolation of n-GaN Field-Effect Transistor Structures
}

G. Dang ${ }^{(1)}$, X. A. Cao ${ }^{(2)}$,F. Ren ${ }^{(1)}$, S. J. Pearton ${ }^{(2)}$, J. $\operatorname{Han}^{(3)}$, A. G. Baca ${ }^{(3)}$, and R. J. Shul ${ }^{(3)}$

(1) Department of Chemical Engineering, University of Florida, Gainesville FL 32611

USA

(2) Department of Materials Science and Engineering, University of Florida, Gainesville FL 32611 USA

(3) Sandia National Laboratories, Albuquerque NM 87185 USA

\begin{abstract}
Multiple-energy (30-325 keV) $\mathrm{O}^{+}$implantation into GaN field-effect transistor structures $\left(\mathrm{n} \sim 10^{18} \mathrm{~cm}^{-3}, 3000 \AA\right.$ thick) can produce as-implanted sheet resistances of $\left.4 \times 10^{12} \Omega /\right\lrcorner$, provided care is taken to ensure compensation of the region up to the projected range of the lowest energy implant. The sheet resistance remains above $10^{7}$ $\Omega /\lrcorner$ to annealing temperatures of $\sim 650^{\circ} \mathrm{C}$ and displays an activation energy of $0.29 \mathrm{eV}$.
\end{abstract} No diffusion of the implanted oxygen was observed for anneals up to $800^{\circ} \mathrm{C}$. 


\section{DISCLAIMER}

This report was prepared as an account of work sponsored by an agency of the United States Government. Neither the United States Government nor any agency thereof, nor any of their employees, make any warranty, express or implied, or assumes any legal liability or responsibility for the accuracy, completeness, or usefulness of any information, apparatus, product, or process disclosed, or represents that its use would not infringe privately owned rights. Reference herein to any specific commercial product, process, or service by trade name, trademark, manufacturer, or otherwise does not necessarily constitute or imply its endorsement, recommendation, or favoring by the United States Government or any agency thereof. The views and opinions of authors expressed herein do not necessarily state or reflect those of the United States Government or any agency thereof. 


\section{DISCLAIMER}

Portions of this document may be illegible in electronic image products. Images are produced from the best available original document. 


\section{Introduction}

Implant isolation has been widely used in compound semiconductor devices for inter-device isolation such as in transistor circuits or to produce current channeling such as in lasers. ${ }^{(1-3)}$ The implantation process can compensate the semiconductor layer either by a damage or chemical mechanism, maintaining a planar device morphology without the need for etched mesa isolation. For damage compensation, the resistance typically goes through a maximum with increased post-implantation annealing temperature as the damage is annealed out and hopping conduction is reduced. At higher temperatures the defect density is further reduced below that required to compensate the material and the resistivity decreases. For chemical compensation, the post-implantation resistance again increases with annealing temperature with a reduction in hopping conduction but it then stabilizes at higher temperatures as a thermally stable compensating deep level is formed. Typically there is a minimum dose (dependent on the doping level of the sample) required for the chemically active isolation species to achieve thermally stable compensation. ${ }^{(4)}$ Thermally stable implant isolation has been reported for $\mathrm{n}$ - and $\mathrm{p}$-type AlGaAs where an Al-O complex is thought to form ${ }^{(4,5)}$ and for C-doped GaAs and AlGaAs where a $\mathrm{C}-\mathrm{N}$ complex is postulated. ${ }^{(6)}$

$\mathrm{N}$-implantation (at doses of $10^{12}-10^{13} \mathrm{~cm}^{-3}$ ) effectively compensates both $\mathrm{p}$ - and n-type GaN. ${ }^{(7-9)}$ For both doping types, the resistance first increases with annealing temperature then reaches a maximum before demonstrating a significant reduction in resistance after a $850^{\circ} \mathrm{C}$ anneal for n-type and a $950^{\circ} \mathrm{C}$ anneal for $\mathrm{p}$-type GaN. This behavior is typical of implant-damage compensation. The defect levels in this Nimplanted material estimated from Arrhenius plots of the resistance/temperature product 
are $0.83 \mathrm{eV}$ for initially n-type and $0.90 \mathrm{eV}$ for initially $\mathrm{p}$-type $\mathrm{GaN}$. These levels are still not at mid-gap, but are sufficiently deep to realize a sheet resistance $>10^{9} \Omega / \square$. He implantation has also been reported to effectively isolate $n$-type $\mathrm{GaN}^{(7)}$, with the material remaining compensated to over $850^{\circ} \mathrm{C}$. Interestingly, $\mathrm{H}$-implanted compensation of $\mathrm{n}$ type GaN is reported to anneal out at $\sim 400^{\circ} \mathrm{C}^{(7)}$ with an anomalous dependence on implant energy. The reason for this is presently not known. In light of this result however, $\mathrm{H}$-implantation in $\mathrm{GaN}$ will require further study, as $\mathrm{H}$ is often the ion of choice for photonic device isolation applications that require deep isolation schemes. Moreover, both the $\mathrm{He}$ and $\mathrm{N}$ isolation appear to rely solely on implantation damage without any chemical compensation effects analogous to those in the O/AlGaAs case. ${ }^{(1,4,5)}$ However, the implantation-induced defects in GaN are more thermally stable than other III-V semiconductor materials, such as GaAs or InP, where the damage levels begin to anneal out below $700^{\circ} \mathrm{C} .^{(\mathrm{l})}$ This may be a result of the higher bandgap of GaN or the more polar nature of the lattice causing more stable defects.

Implant isolation of the In-containing nitrides (InN, InGaN and InAIN) was first reported using F-implantation. ${ }^{(8)}$ That work showed that InN did not demonstrate significant compensation while the ternaries increased in sheet resistance by roughly an order-of-magnitude after a $500^{\circ} \mathrm{C}$ anneal. Data from a more extensive study of $\mathrm{In}_{\mathrm{x}} \mathrm{Ga}_{\mathrm{l}-\mathrm{x}} \mathrm{N}$ implant isolation for varying $\mathrm{In}$-composition using $\mathrm{N}$ - and F-implantation showed that InGaN ternaries only realize a maximum of a 100 fold increase in sheet resistance independent of ion species after a $500^{\circ} \mathrm{C}$ anneal. Pure InN shows a higher increase of 3 orders-of-magnitude but still only achieves a maximum sheet resistance of $\left.10^{4} \Omega /\right\rfloor$. This may be high enough for some photonic device current-guiding 
applications but is not sufficient for inter-device isolation in electronic circuits. The damage levels created by $\mathrm{N}$-implantation are estimated from an Arrhenius plot of the resistance/temperature product to be a maximum of $390 \mathrm{meV}$ below the conduction band. ${ }^{(9)}$ The defect level is high in the energy gap, not near mid-gap as is ideal for implant compensation. The position of the damage level is analogous to the defect position reported for implant compensated n-type InP and InGaAs ${ }^{(10)}$ but different from the damage-associated, mid-gap states created in GaAs and AlGaAs. ${ }^{(4,5)}$

InAIN, in contrast to InGaN, can be highly compensated with $\mathrm{N}$ - or $\mathrm{O}$ implantation with over a three order-of-magnitude increase in sheet resistance after a $600-700^{\circ} \mathrm{C}$ anneal while F-implantation produces only one order-of-magnitude increase in sheet resistance. ${ }^{(8,11)}$ The compensating level in InAlN is also high in the bandgap with the deepest level estimated from Arrhenius plots as being $580 \mathrm{meV}$ below the conduction band edge in high dose $\mathrm{N}$-isolated material, however it is sufficiently deep to achieve highly compensated material. ${ }^{(11)}$ The enhanced compensation for $\mathrm{N}$ - and O-implantation, as compared to F-implantation in InAlN, suggests some chemical component to the compensation process. For $\mathrm{N}$-implantation a reduction in $\mathrm{N}$-vacancies, that are thought to play a role in the as-grown n-type conduction, may explain the enhanced compensation. For O-implantation, the enhanced compensation may be the result of the formation of an $\mathrm{Al}-\mathrm{O}$ complex as is thought to occur in O-implanted AlGaAs. ${ }^{(5,6)}$

The recent emphasis in developing GaN electronics for high power, high temperature applications means there is a need to achieve effective device isolation processes using implantation. Very effective isolation of $\mathrm{AlGaN} / \mathrm{GaN}$ heterostructure field effect transistor (HFET) structures has been achieved using a combined $\mathrm{P}^{+} / \mathrm{He}^{+}$ 
implant process. ${ }^{(12)}$ The groups of Asbeck and Lau at UCSD demonstrated that a dual energy $(75 / 180 \mathrm{keV}) \mathrm{P}^{+}$implant (doses of $5 \times 10^{11}$ and $2 \times 10^{12} \mathrm{~cm}^{-2}$, respectively), followed by a $75 \mathrm{keV} \mathrm{He}^{+}$implant $\left(6 \times 10^{13} \mathrm{~cm}^{-2}\right)$ was able to produce a sheet resistance of $\sim 10^{12}$ $\Omega / \sqcup$ in AlGaN/GaN structures with $1 \mu \mathrm{m}$ thick undoped GaN buffers. The temperature dependence of the resistivity showed an activation energy of $0.71 \mathrm{eV}^{(13)}$,consistent with past measurements of deep states induced in GaN by implant damage. ${ }^{(14)}$

In this paper we report on the creation of very high resistance $\sim 4 \times 10^{12}$ $\Omega / \square$ regions in $\mathrm{n}-\mathrm{GaN}$ by $\mathrm{O}$ implantation. The resistance stays above $10^{9} \Omega / \square$ for annealing to $\sim 500^{\circ} \mathrm{C}$ and to measurement temperatures of $\sim 200^{\circ} \mathrm{C}$.

\section{Experimental}

The layer structure shown in Figure 1 was grown on c-plane $\mathrm{Al}_{2} \mathrm{O}_{3}$ substrates by rf plasma-assisted Molecular Beam Epitaxy. ${ }^{(15)}$ The uppermost n-GaN was Si-doped to produce a carrier concentration of $\sim 10^{18} \mathrm{~cm}^{-3}$. This structure simulates a GaN metal semiconductor field effect transistor (MESFET) or metal-oxide semiconductor FET (MOSFET) layer design. In some structures, $490 \AA \AA$ of Ti was deposited by e-beam evaporation on top of the $\mathrm{GaN}$, and the implant performed through that layer. This procedure enabled us to achieve better near-surface isolation properties. The implant scheme consisted of 5 different conditions, i.e. $\mathrm{O}^{+}$ions implanted at the following doses and energies: $30 \mathrm{keV}, 3 \times 10^{12} \mathrm{~cm}^{-2} ; 60 \mathrm{keV}, 5 \times 10^{12} \mathrm{~cm}^{-2} ; 125 \mathrm{keV}, 9 \times 10^{12} \mathrm{~cm}^{-2} ; 200 \mathrm{keV}$, $9 \times 10^{12} \mathrm{~cm}^{-2}$ and $325 \mathrm{keV}, 2 \times 10^{13} \mathrm{~cm}^{-2}$. The total $\mathrm{O}^{+}$dose was therefore $4.6 \times 10^{13} \mathrm{~cm}^{-2}$. The ion profiles were simulated by P-CODE ${ }^{\mathrm{TM}}$, while the displacement damage was simulated by the Transport-of-Ions-In-Matter (TRIM) code. The sheet resistance was 
obtained from Transmission Line Measurements (TLM) using Ti/Au contacts alloyed at $800^{\circ} \mathrm{C}$ prior to the implantation step.

\section{Results and Discussion}

Figure 2 shows the calculated ion profiles for the multiple-energy $\mathrm{O}^{+}$implant scheme into bare $\mathrm{GaN}$. Note that there is a region at the immediate surface $(\leq 250 \AA)$ that has a much lower ion concentration, simply because the projected range of the $30 \mathrm{keV} \mathrm{O}^{+}$ ions is $\sim 300 \AA$. It is important to know the expected atom displacement density in this surface region, because it is the ion damage that actually produces the high resistance behavior in implanted semiconductors. ${ }^{(1)}$

The vacancy concentration profile calculated from the nuclear stopping energy deposition by the implanted $\mathrm{O}^{+}$ions is shown in Figure 3. This also shows that the nearsurface region does receive as much cumulative damage as the region from $250-3000 \AA$. Adequate coverage of this near-surface region is a common problem in implant isolation processes because conventional implant systems typically have minimum operating voltages in the $20-30 \mathrm{keV}$ range.

$t$

One solution tophis problem is to implant through a surface layer which acts to move the projected range of the lowest energy implant closer to the semiconductor surface. Titanium is a good choice, since it can be readily removed after the implant step with HF solutions. Moreover, ion mixing effects are not significant until doses $\geq 10^{16}$ $\mathrm{cm}^{-2}$.

Figure 4 shows the calculated ion profiles for the $\mathrm{O}^{+}$implant scheme through the Ti over-layer and into the underlying GaN. Note that the projected range of the $30 \mathrm{keV}$ 
$\mathrm{O}^{+}$implant is now just at the metal-semiconductor interface, effectively reducing the energy of ions reaching the GaN. The calculated vacancy profile is now relatively uniform throughout the doped GaN layer as shown in Figure 5.

The implanted samples were subsequently annealed for 30 secs at temperatures up to $800^{\circ} \mathrm{C}$. Figure 6 shows the evolution of the sheet resistance with annealing temperature in the sample implanted without the Ti over-layer. The as-implanted sheet resistance was $8 \times 10^{10} \Omega / \square$, and gradually decreased over the entire annealing temperature range. A general rule of thumb for achieving acceptable device isolation is that the implanted region should have a sheet resistance $\geq 10^{7} \Omega / \square .^{(1)}$ In this implant process, sheet resistances above this value were achieved for annealing temperatures up to $\sim 650{ }^{\circ} \mathrm{C}$. Note that even for $800{ }^{\circ} \mathrm{C}$ anneals, the sheet resistance is still two orders of magnitude above the unimplanted value $\left(10^{4} \Omega / \sqsupset\right)$.

A similar plot is shown in Figure 7 for the sample implanted with $\mathrm{O}^{+}$ions through the Ti over-layer. In this case, a higher maximum sheet resistance was achieved $\left(4 \times 10^{12}\right.$ $\Omega / \sqcup)$. This is the highest value reported in GaN. The compensation mechanism is creation of deep electron traps that remove electrons from the conduction band. Upon annealing, some of these damage-related traps are removed, allowing electrons to be returned to the conduction band. The use of the Ti over-layer allows better compensation in the near-surface region and hence a higher as-implanted sheet resistance. The subsequent evolution of the sheet resistance with annealing temperature is similar to the case of implantation without the Ti over-layer, except that the absolute value is larger up to $\sim 600^{\circ} \mathrm{C}$. Secondary Ion Mass Spectrometry (SIMS) measurements on the samples 
showed that the implanted oxygen did not have any detectable redistribution at $800^{\circ} \mathrm{C}$, consistent with the low diffusivities reported previously. ${ }^{(14)}$

The sheet resistance of the implanted GaN showed a thermal activation energy of $0.29 \mathrm{eV}$, as determined by temperature dependent resistance measurements (Figure 8). This gives a rough estimate of the position of the Fermi level in the material. It is somewhat different from the value reported in implanted AlGaN/GaN HFETs $(0.71$ $\mathrm{eV})^{(12)}$, and is probably at least partially related to the smaller bandgap of the $\mathrm{GaN}$. It is likely that the energy level of traps created in implanted material will depend on the dominant impurities present and on the chemical nature of the implanted species. ${ }^{(1)}$

\section{Summary and Conclusions}

The main conclusions of our study can be summarized as follows:

1. Sheet resistances as high as $4 \times 10^{12} \Omega / \square$ can be achieved in $\mathrm{O}^{+}$implanted $\mathrm{n}$-GaN structures when care is taken to ensure ion-induced compensation in the near-surface region by implantation through an over-layer.

2. The sheet resistance remains above $10^{7} \Omega / \square$ until annealing temperatures of $\sim 650^{\circ} \mathrm{C}$, which defines the thermal stability of acceptable $\mathrm{GaN}$ device isolation.

3. The activation energy of sheet resistance in the $\mathrm{O}^{+}$implanted $\mathrm{GaN}$ is 0.29 $\mathrm{eV}$. This is well below the desired mid-gap value, but due to the large gap of $\mathrm{GaN}$, the sheet resistance is more than sufficient for device isolation. 


\section{Acknowledgements}

The work at UF is partially supported by a DARPA/EPRI grant (D. Radack/J. Melcher), contract MDA 972-98-1-0006, monitored by ONR (J. C. Zolper), and by an

NSF grant, DMR 97-32865 (L. D. Hess). Sandia is a multi-program laboratory operated by Sandia Corporation, a Lockheed-Martin company, for the US Department of Energy under grant no. DEAC 04-94-AL-85000. 


\section{References}

1. S. J. Pearton, Mat. Sci. Rep. $\underline{4}, 313$ (1990).

2. M. Orenstein, N. G. Stoffel, A. C. Von Lehmen, J. P. Harbison and L. T. Florez, Appl. Phys. Lett. 59, 31 (1991).

3. K. L. Lear, R. P. Schneider, K. D. Choquette, S. P. Kilcoyne, J. J. Figiel and J. C. Zolper, IEEE Photonic Tech. Lett. 6 , 1503 (1994).

4. J. C. Zolper, A. G. Baca and S. A. Chalmers, Appl. Phys. Lett. 62, 2536 (1993).

5. S. J. Pearton, M. P. Ianuzzi, C. L. Reynolds, Jr. and L. Peticolas, Appl. Phys. Lett. $\underline{52}$, 395 (1988).

6. J. C. Zolper, M. E. Sherwin, A. G. Baca and R. P. Schneider, Jr., J. Electron. Mat. $\underline{24}$, $21(1995)$.

7. S. C. Binari, H. B. Dietrich, G. Kelner, L. B. Rowland, K. Doverspike and K. D. Wickenden, J. Appl. Phys. 78 , 3008 (1995).

8. S. J. Pearton, C. R. Abernathy, P. W. Wisk, W. S. Hobson and F. Ren, Appl. Phys. Lett. $\underline{63}, 1143$ (1993).

9. J. C. Zolper, S. J. Pearton, C. R. Abernathy and C. B. Vartuli, Appl. Phys. Lett. 66, 3042 (1995).

10. S. J. Pearton, C. R. Abernathy, M. B. Panish, R. A. Hamm and L. M. Lunardi, J. Appl. Phys. $\underline{66}, 656$ (1989)

11. J. C. Zolper, S. J. Pearton, C. R. Abernathy and C. B. Vartuli, Mat. Res. Soc. Symp. Proc. $\underline{378}, 408$ (1995).

12. G. Hanington, Y. Hsin, Q. Z. Liu, P. M. Asbeck, S. S. Lau, M. A. Khan, J. W. Yang and Q. Chen, Electron. Lett. 34, 193 (1998). 
13. S. J. Pearton, C. R. Abernathy, C. B. Vartuli, J. C. Zolper, C. Yuan and R. A. Stall, Appl. Phys. Lett. 67, 1435 (1995).

14. J. C. Zolper, J. Cryst. Growth $\underline{178}, 175$ (1997).

15. J. M. Van Hove, R. Hickman, J. J. Klaassen, P. P. Chow and P. P. Ruden, Appl. Phys. Lett. $\underline{70}, 282$ (1997).

16. F. Ren, S. J. Pearton, C. R. Abernathy, P. Wisk, T. R. Fullowan, J. Lothian and R. Esaqui, Semicond. Sci. Technol. $\underline{8}, 413$ (1993). 


\section{Figure Captions}

Figure 1. Schematic of GaN layer structure (top) and scanning electron micrograph (SEM) of TLM pattern (bottom).

Figure 2. Calculated ion profiles in $\mathrm{GaN}$ implanted with five separate $\mathrm{O}^{+}$implants at energies from $30-325 \mathrm{keV}$.

Figure 3. Calculated vacancy concentration in $\mathrm{GaN}$ implanted with five separate $\mathrm{O}^{+}$ implants at energies from $30-325 \mathrm{keV}$.

Figure 4. Calculated ion profiles in a Ti/GaN sample implanted with five separate $\mathrm{O}^{+}$ implants at energies from $30-325 \mathrm{keV}$.

Figure 5. Calculated vacancy concentration in a $\mathrm{Ti} / \mathrm{GaN}$ sample implanted with five separate $\mathrm{O}^{+}$implants at energies from $30-325 \mathrm{keV}$.

Figure 6. Annealing temperature dependence of sheet resistance in $\mathrm{O}^{+}$implanted $\mathrm{GaN}$. The implant was performed directly into the GaN.

Figure 7. Annealing temperature dependence of sheet resistance in $\mathrm{O}^{+}$implanted $\mathrm{GaN}$. The implant was performed through a Ti over-layer.

Figure 8. Measurement temperature dependence of sheet resistance in $\mathrm{O}^{+}$implanted GaN. 

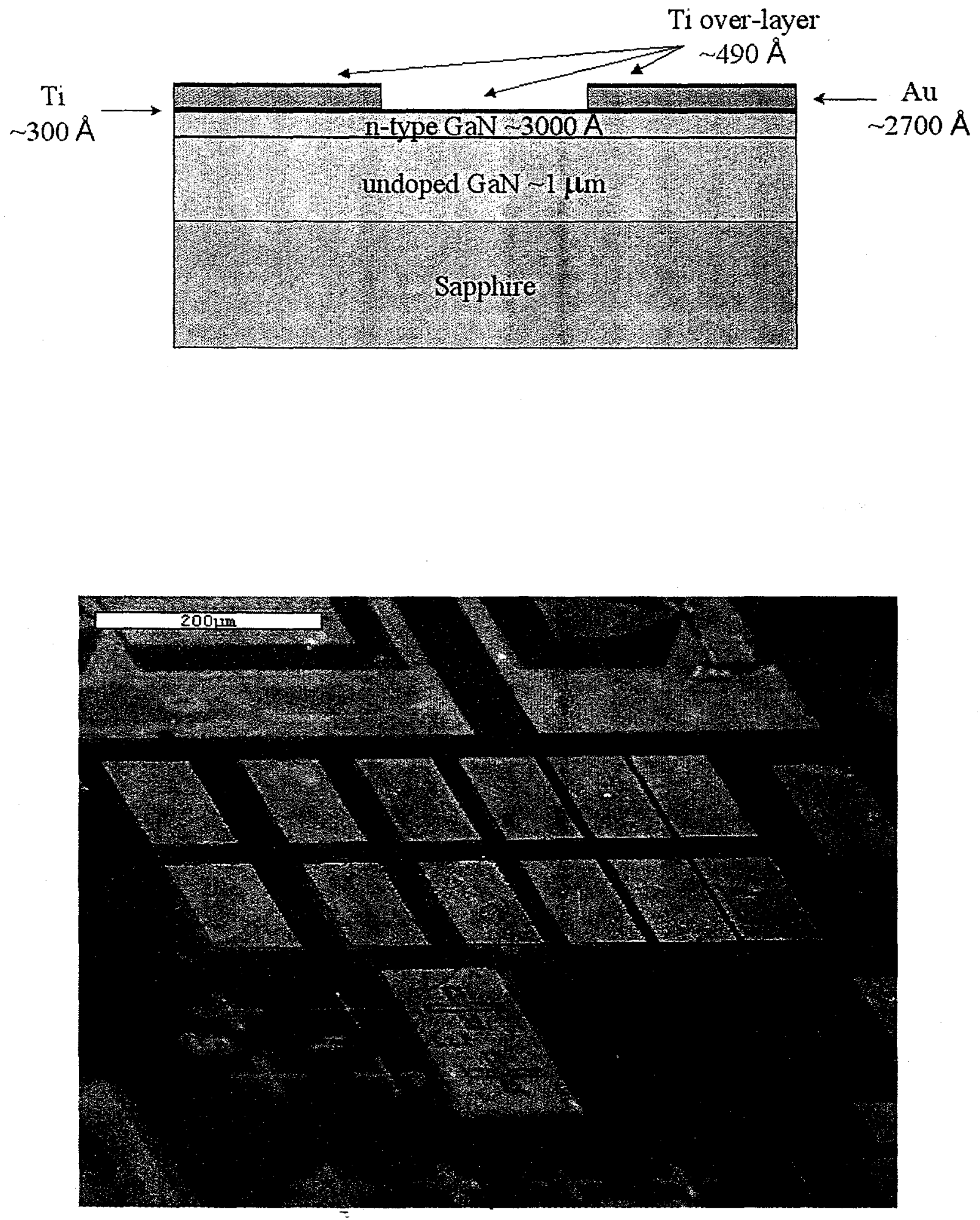


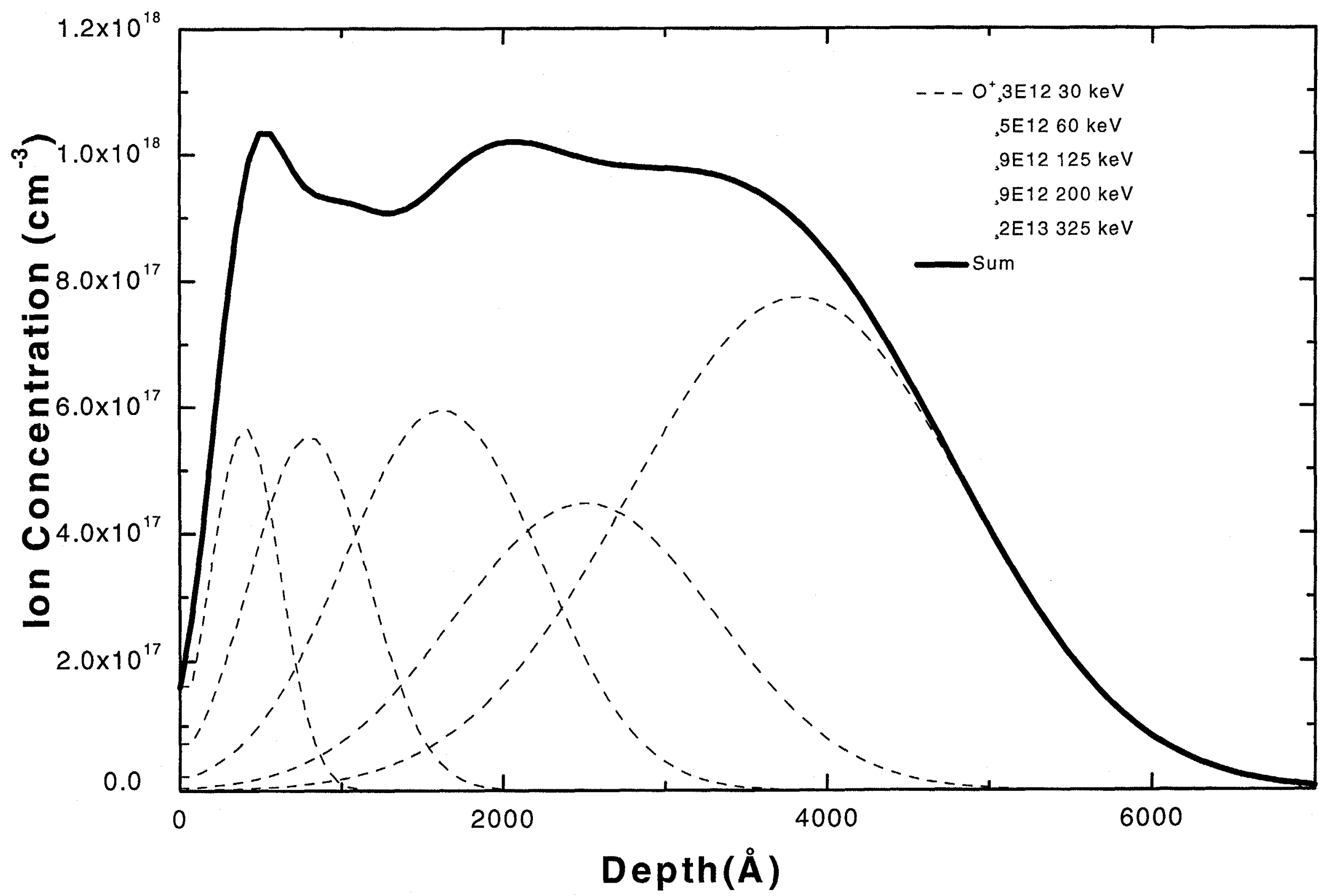




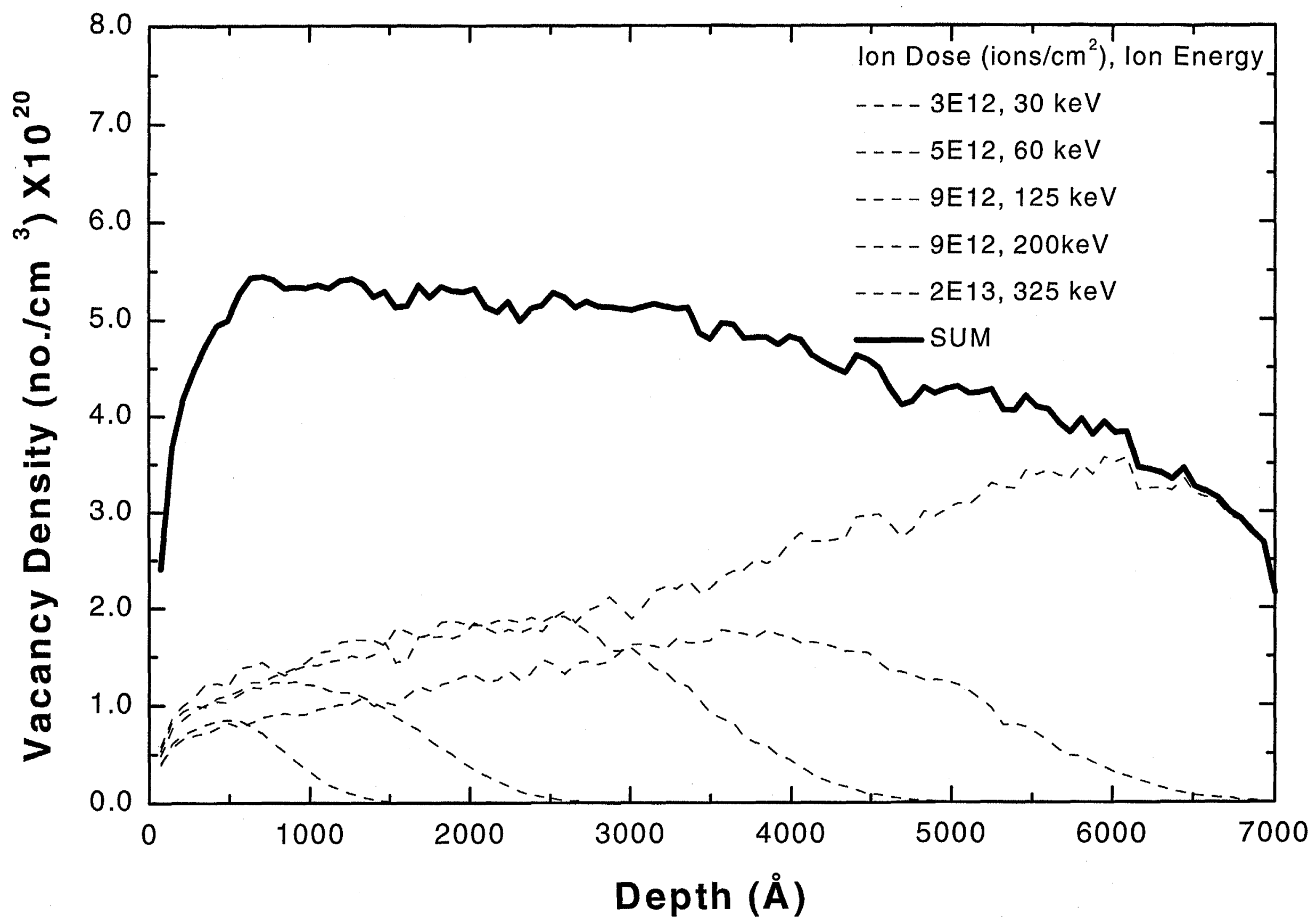




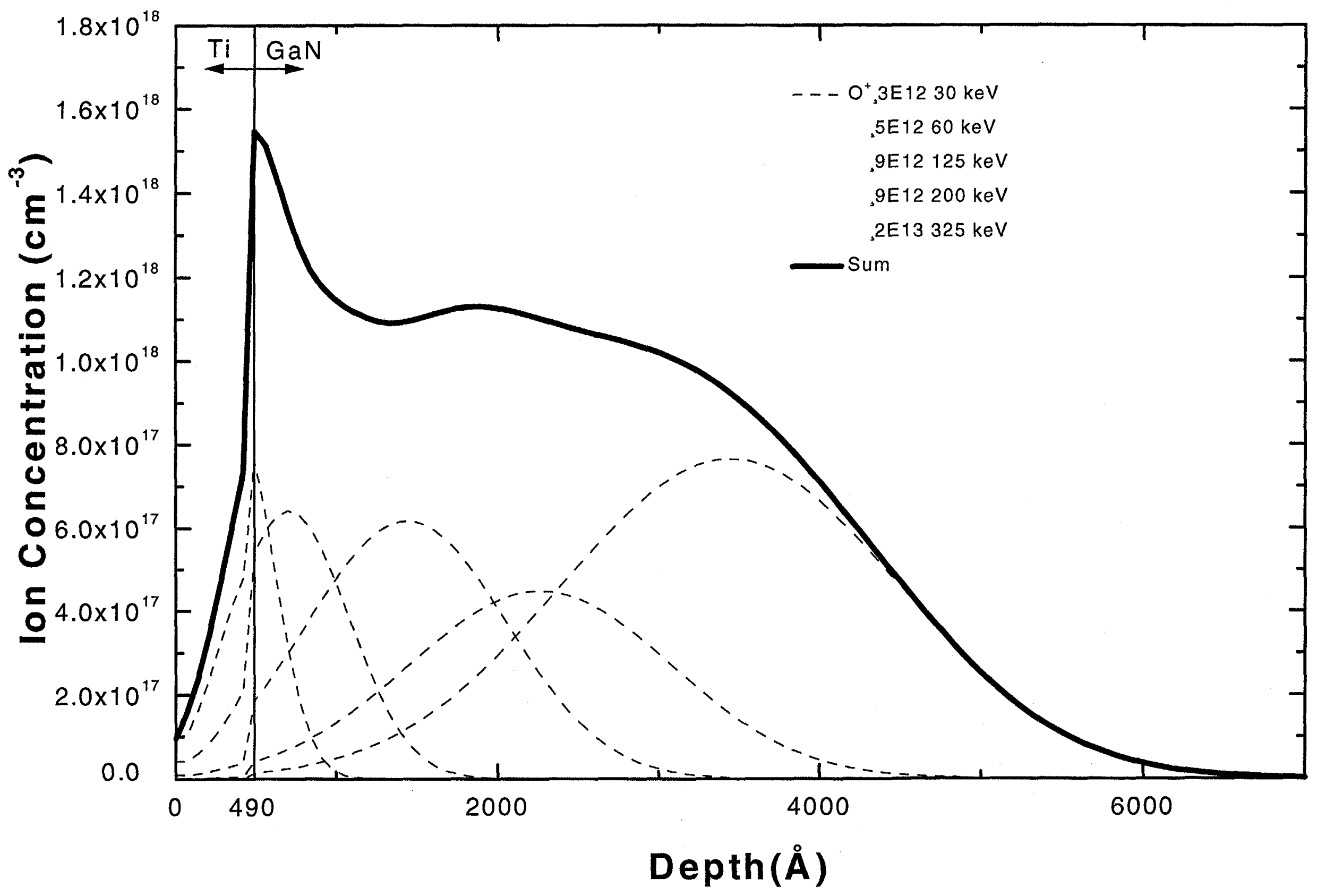




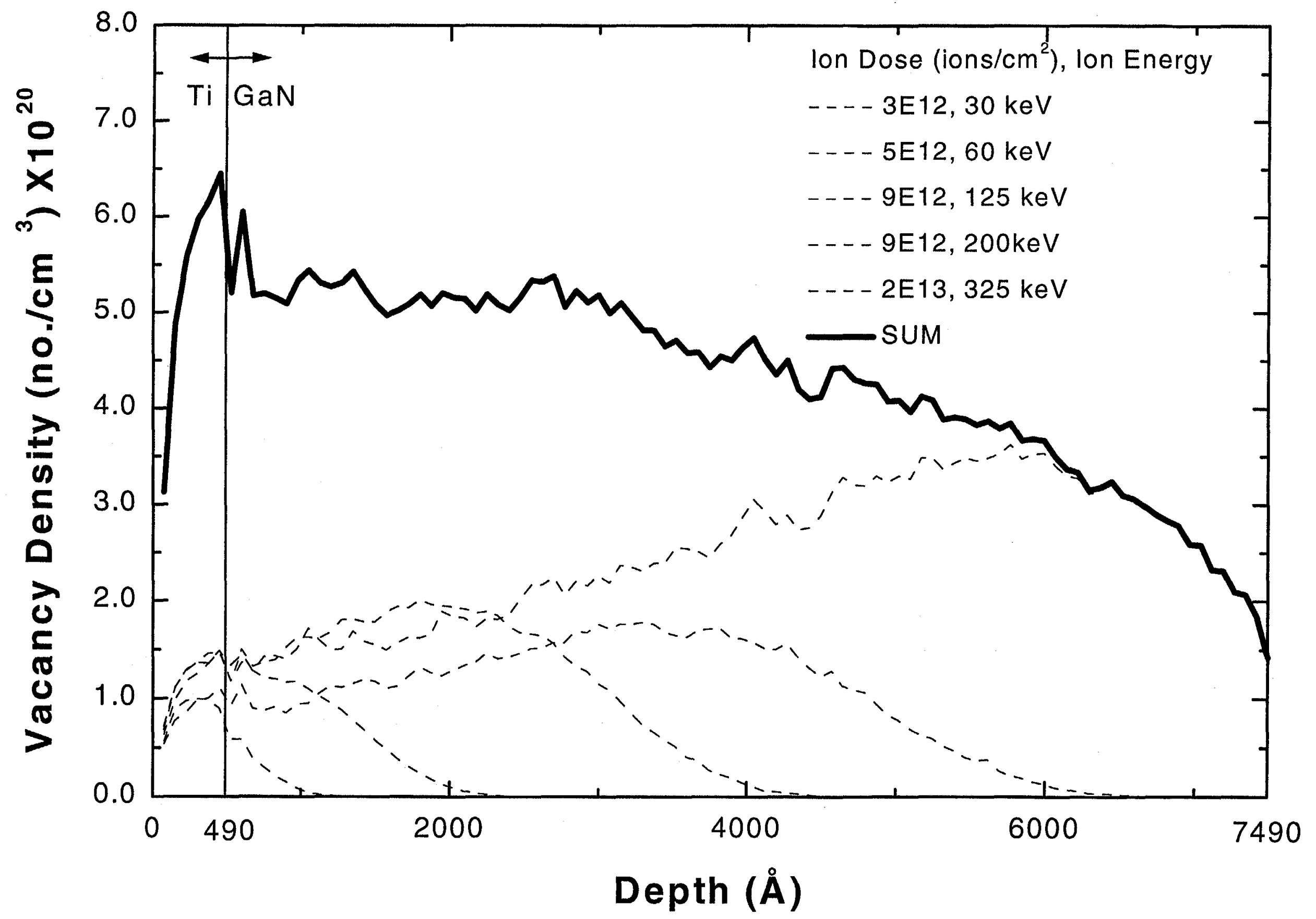




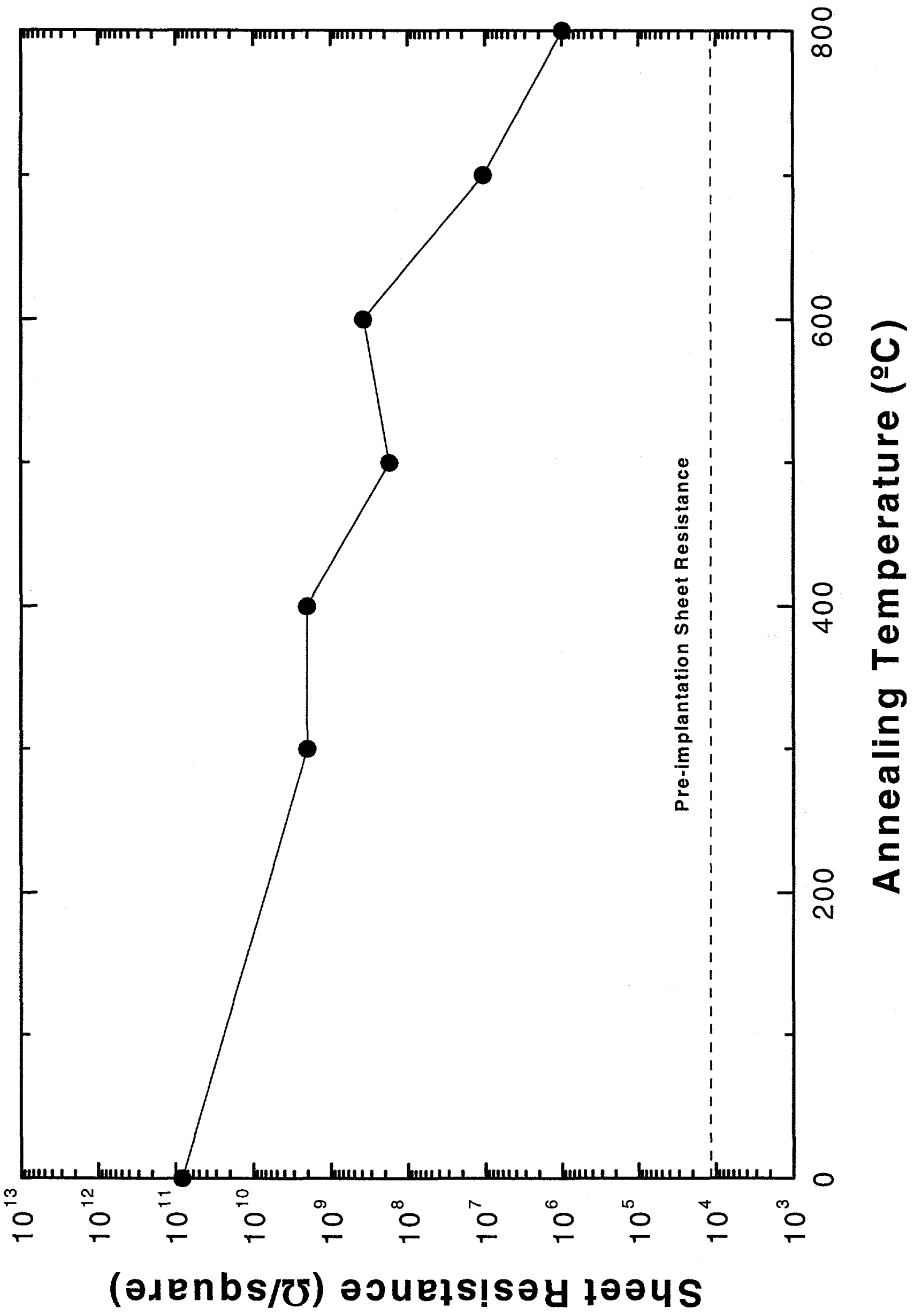




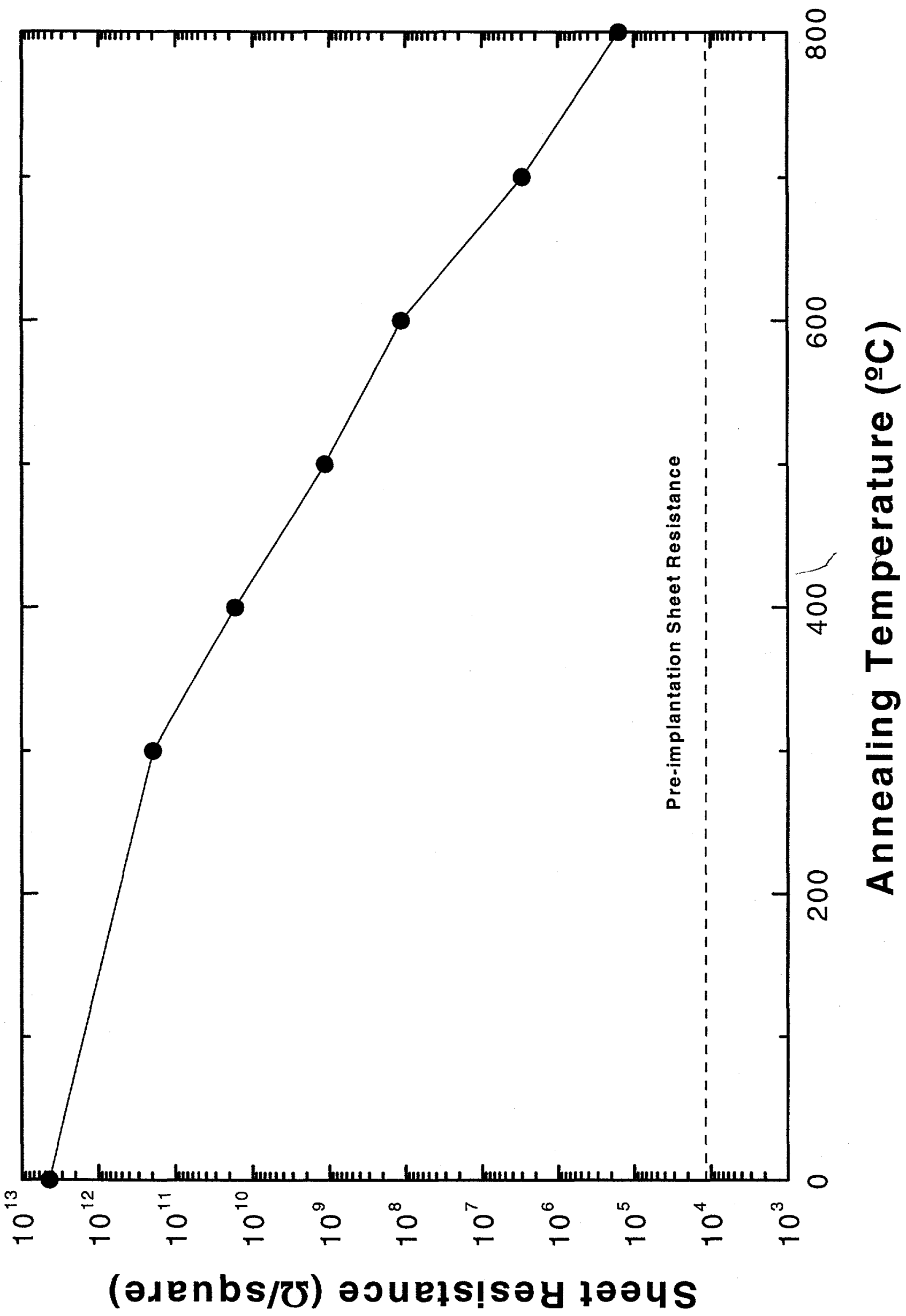




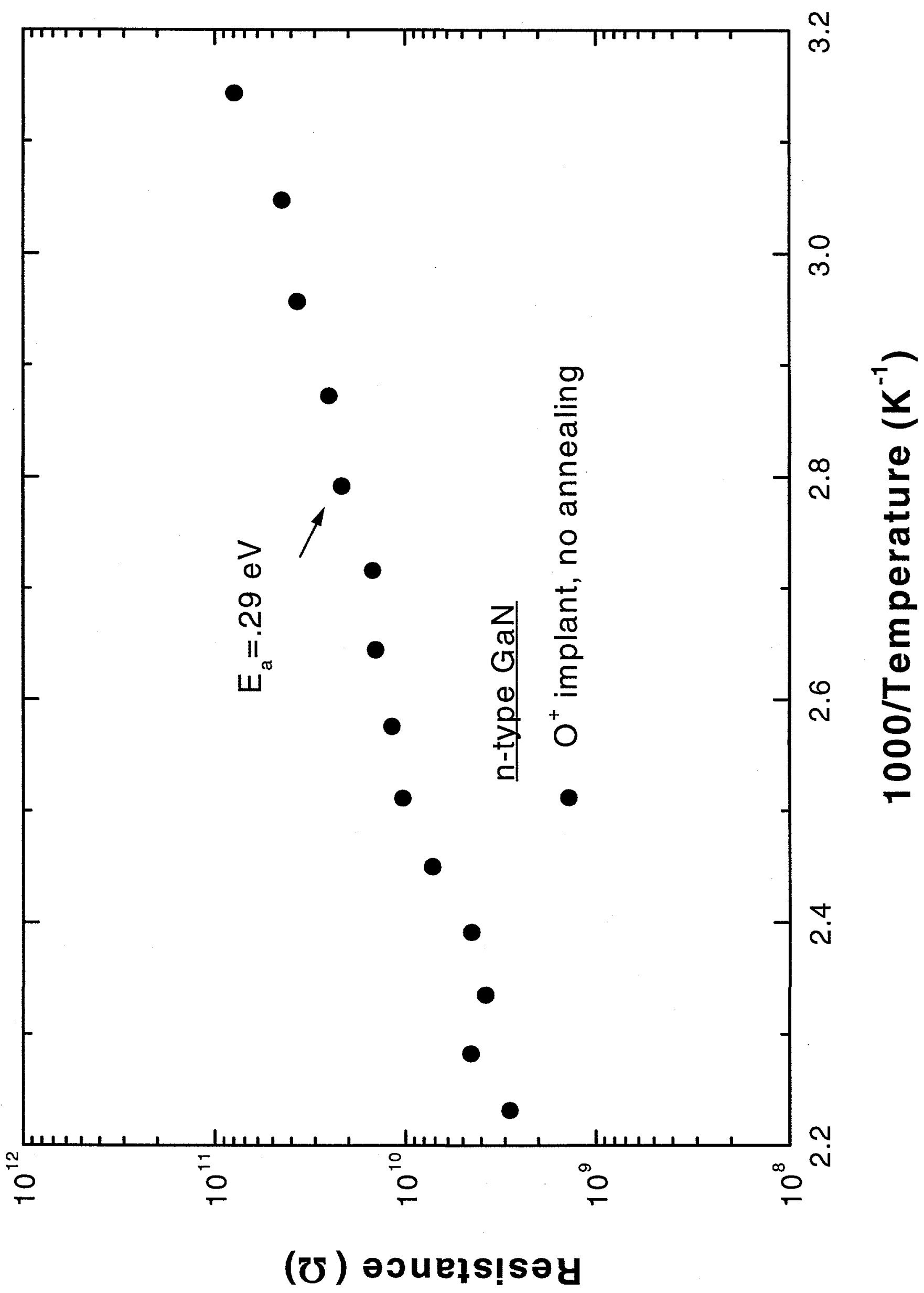

